\title{
Applying a Midwifery-Specific Decision-Making Tool to Midwives' Clinical Reasoning and Midwifery Practice When Managing a Woman's Perineum in Labor: An Exploratory Study
}

\author{
Elaine Jefford, Julie Jomeen, Frances Guy, Belinda Newcombe, and \\ Colin Martin
}

INTRODUCTION: Many of the risk factors for perineal trauma are modifiable, and midwives are in an ideal position to mitigate such risks. To date, no investigation using a midwifery-specific decision-making tool has sought to determine how midwives make decisions within a midwifery philosophy/context or identify the factors that may contribute to that decision making about perineal management. We sought to apply such a tool to midwives' narratives and explore their clinical reasoning and midwifery practice when managing a woman's perineum in labor.

METHODS: A qualitative interview-based study with practicing midwives in one regional Australian maternity unit was conducted. The decision-making matrix specified by a psychometrically robust and validated measure of clinical decision making and midwifery practice-guided analysis.

RESULTS: Effective clinical decision making in response to perineal trauma is contingent on a heuristic and individualized "working hypothesis" that combines distinct elements of an optimal clinical decision-making process. Midwives' narratives highlighted their ability to engage in some form of clinical reasoning. Some elements of midwifery practice was lacking within several midwives' narratives, thus resulting in them abdicating their professional role.

CONCLUSION: The manner and processes by which midwives engage effectively with perineal management are complex. However, a significant influence on this process appears to be recollections from original training in perineal management, which appears to be largely rote and taught by example. We recommend balance between practical experience and synthesis with current evidence within a midwifery philosophy to optimize perineal care and risk modification.

KEYWORDS: clinical reasoning; decision making; midwifery education; perineal; midwifery abdication

\section{INTRODUCTION}

Perineal trauma is a common phenomenon associated with childbirth around the world (Kettle \& Tohill, 2011); it may occur through surgical intervention or spontaneously (Dahlen, 2007). Birth-related perineal trauma appears to be a perversive element of childbirth with approximately $80 \%$ of nulliparous, and $30 \%$ of multiparous women experience it (Kettle \& Tohill, 2011; Lumbiganon et al., 2010). In 2010, 70.3\% Australian women suffered some degree of perineal trauma following a vaginal birth (Zeiki, Hilder, \& Sullivan, 2010) and in 2015 UK data identified that $85 \%$ of women sustain some degree of trauma (Bulchandani, Watts, Sucharitha, 
Yates, \& Ismail, 2015). Aasheim, Nilsen, Lukasse, and Reinar (2011) noted associated postnatal morbidities to be perineal pain, dyspareunia, and fecal incontinence. Psychological consequences include negative maternal body image and deleterious transition to motherhood, negative feelings of "self," a sense of loss, and feelings of guilt (Priddis, Schmied, \& Dahlen, 2014), with a concomitant impact on a woman's ability to undertake baby-care tasks and breastfeed (Priddis et al., 2013).

Multiple studies have considered modifiable versus non-modifiable risk factors for perineal trauma (Aasheim et al., 2011; Komorowski et al., 2014; Mazza et al., 2007; Wang, Jayasekara, \& Warland, 2015; Zare, Pasha, \& Faramarzi, 2014; Zeiki et al., 2010). Nonmodifiable risk factors are well documented across the spectrum of research literature from Cochrane Reviews to case studies (Gurol-Urganci et al., 2013; Hauck, Lewis, Nathan, White, \& Doherty, 2015; Kapoor, Thakar, \& Sultan, 2015; Kettle \& Tohill, 2011; Komorowski et al., 2014; Revicky, Nirmal, Mukhopadhyay, Morris, \& Nieto, 2010; Royal College of Obstetricians and Gynaecologists [RCOG], 2015). The quality of the evidence surrounding modifiable risk factors is somewhat varied and lacking in consensus (Aasheim et al., 2011; Cluett \& Burns, 2009; Gupta, Hofmeyer, \& Shehmar, 2012; Ratier, Balenbois, Letouzey, Marès, \& de Tayrac, 2015; RCOG, 2015; Wang et al., 2015), which places midwives in a vulnerable position when trying to provide best care based on evidence. This vulnerability is further compounded as midwives, who work within a womancentered philosophy, have to comply with professional, regulatory and legal governance which includes providing quality, safe, evidence-informed care (Nursing and Midwifery Board of Australia, 2006, 2007; International Confederation of Midwives [ICM], 2008, 2010, 2011; Nursing and Midwifery Council, 2012). Hence, when facing conflicting evidence and opinion, the clinical reasoning and decision-making process becomes more complicated. In such instances, midwives instinctively draw upon their intuition and experiential knowledge, which potentially places them in a vulnerable position (Jefford \& Jomeen, 2015). This, therefore, has implications for the quality and safety of care provision for the women.

Several studies have explored midwives' decision making and perineal management (Cioffi, Arundell, \& Swain, 2009, 2010; Dahlen \& Homer, 2008; Spendlove, 2005), but no study has utilized a validated psychometric midwifery decision-making tool. No study has disentangled which aspects of midwifery decision making are utilized and prioritized within the philosophy of midwifery and the context of a potentially ambiguous evidence base. The Enhancing Decision-Making and Assessment in Midwifery (EDAM) is a midwiferyspecific tool, which measures/assesses midwives' ability to undertake decision-making processes in the second stage of labor (Jefford, Jomeen, \& Martin, 2016). EDAM is a robust and reliable psychometric instrument for measuring midwifery decision making, validated via a cross-sectional design study using expert panels in two countries. This study has been reported elsewhere (Jefford et al., 2016). EDAM (Jefford et al., 2016) identifies two necessary and sufficient conditions required to facilitate optimal midwifery decision making during 2nd stage labor. Factors which may or may not influence the final decision are under the identified conditions of Good Clinical Reasoning and Good Midwifery Practice. The midwifery philosophy is entrenched within EDAM.

This exploratory study sought to apply the EDAM tool to midwives' narratives about perineal management with the aim of consistently assessing their clinical reasoning and factors, which may or may not influence their final decision making related to perineal management. Findings from this exploratory study may be potentially useful to underpin future study development in this area.

\section{METHODS}

\section{Procedure}

Ethics approval was via a university and local health district. Dissemination of an expression of interest letter occurred in one regional Australian maternity unit that has approximately 1,200 births per annum. Interested midwives received a study information sheet. The inclusion criteria was limited to midwives who had been primary accoucher, within the past 6 months, where perineal integrity was not maintained. Midwives chose a pseudonym to ensure confidentiality and anonymity.

\section{Sampling}

Nine practicing midwives consented to take part in the study; two subsequently were withdrawn due to data quality issues. These issues related to the midwives using the interviews as an opportunity to focus on the actions of medical practitioners present rather than their own clinical reasoning and actions. Data were analyzed upon completion of each interview. This aided the researchers 


\begin{tabular}{|c|c|c|c|c|c|}
\hline $\begin{array}{l}\text { Please tick the box that represents the level to which } \\
\text { you agree/disagree with the following statements in } \\
\text { relation to the following clinical vignette }\end{array}$ & $\begin{array}{l}\text { Strongly } \\
\text { Agree }\end{array}$ & Agree & \begin{tabular}{l|} 
Neither \\
Agree \\
nor \\
disagree
\end{tabular} & Disagree & $\begin{array}{l}\text { Strongly } \\
\text { Disagree }\end{array}$ \\
\hline \multicolumn{6}{|l|}{ CLINICAL REASONING } \\
\hline \multicolumn{6}{|l|}{ Clinical Reasoning Process $^{1}$} \\
\hline \multicolumn{6}{|l|}{$\begin{array}{l}\text { 1. Cue acquisition }{ }^{\dagger}- \\
\text { appears to be comprehensive }\end{array}$} \\
\hline \multicolumn{6}{|l|}{$\begin{array}{l}\text { 2. Cue clusteringt† - } \\
\text { appears to be comprehensive }\end{array}$} \\
\hline \multicolumn{6}{|l|}{$\begin{array}{l}\text { 3. Cue Interpretationt+† - Generating multiple } \\
\text { hypotheses - if relevant }\end{array}$} \\
\hline \multicolumn{6}{|l|}{$\begin{array}{l}\text { 4. Focused cue acquisition - if needed and relevant to } \\
\text { hypothesis }\end{array}$} \\
\hline \multicolumn{6}{|l|}{ 5. Ruling in and Ruling out hypotheses - if relevant } \\
\hline \multicolumn{6}{|l|}{ Integration and Intervention } \\
\hline \multicolumn{6}{|l|}{$\begin{array}{l}\text { 6. Evaluates treatment options relevant to the } \\
\text { diagnosis - if relevant }\end{array}$} \\
\hline \multicolumn{6}{|l|}{ 7. Prescribes and/or implements planned care } \\
\hline \multicolumn{6}{|l|}{ 8. Evaluates outcomes } \\
\hline \multicolumn{6}{|l|}{ 9. Uses intuition to aid decision-making } \\
\hline \multicolumn{6}{|l|}{ MIDWIFERY PRACTICE } \\
\hline \multicolumn{6}{|l|}{ Woman's relationship with midwife } \\
\hline \multicolumn{6}{|l|}{ 1. Stays in the room with the woman in labour } \\
\hline \multicolumn{6}{|l|}{ 2. Shares a common, known goal with the woman } \\
\hline \multicolumn{6}{|l|}{ 3. Trusts the woman and her body } \\
\hline \multicolumn{6}{|l|}{ General midwifery practice } \\
\hline \multicolumn{6}{|l|}{$\begin{array}{l}\text { 4. Honest and complete information sharing with } \\
\text { woman/partner }\end{array}$} \\
\hline \multicolumn{6}{|l|}{$\begin{array}{l}\text { 5. Accountability for own professional behaviour in } \\
\text { accordance with professional frameworks }\end{array}$} \\
\hline \multicolumn{6}{|l|}{$\begin{array}{l}\text { 6. Skills in negotiating with medical staff or senior } \\
\text { midwifery staff }\end{array}$} \\
\hline \multicolumn{6}{|l|}{$\begin{array}{l}\text { 7.Assumes appropriate responsibility for } \\
\text { woman/baby's well-being in labour }\end{array}$} \\
\hline \multicolumn{6}{|l|}{8 Shows reflexive practice } \\
\hline \multicolumn{6}{|l|}{$\begin{array}{l}\text { 9. When the woman and midwife disagree about care } \\
\text { takes appropriate action (documentation and } \\
\text { consultation) }\end{array}$} \\
\hline 10. The woman is the final decision-maker & & & & & \\
\hline
\end{tabular}

Based on the above, we would now like you to tick one box below to indicate whether you think the midwife's action/s in this story represents

Good decision-making and Good midwifery practice (optimal decision-making)

Good decision-making and Poor midwifery practice

Poor decision-making and Good midwifery practice

Poor decision-making and Poor midwifery practice

\footnotetext{
$1+$ Cue Acquisition: Sensory data that is collected; signs and symptoms

†+ Cue Clustering: Cues that are possibly related are considered together; pulse and respiration with blood pressure

t+† Cue Interpretation: Using knowledge to understand the meaning of cues, to explain the cue cluster/s (provisional \& differential diagnosis)
}

FIGURE 1 Enhancing Decision Making and Assessment in Midwifery (EDAM). 
in reaching the conclusion that data saturation occurred as no new data were transpiring; thus, no further recruitment occurred.

\section{Data Collection}

A demographic questionnaire provided information about age, level of qualification, length of midwifery practice, and type of perineal trauma sustained. Oneon-one interviews asked midwives to describe one experience of being primary accoucher where perineal integrity was preserved and one experience of being primary accoucher for a woman during birth where perineal integrity was not preserved. Prompts such as "what were you taking into consideration when you made that decision?" and "was that important to you and why?" and "what influenced you to put your hands on the perineum?" were utilized to provide a deeper exploration of the context of practice or the midwives' perceptions of their decisions and actions and their "in the moment" thoughts as they undertook their clinical reasoning in their unfolding narratives. This resulted in 14 narratives.

\section{Data Analysis}

Sample characteristics were analyzed using descriptive methods. Verbatim transcription of the interviews occurred. Participants validated their transcribed interview. Three researchers read and applied the EDAM tool to each of the transcripts (Jefford et al., 2016). This occurred by focusing on the words the midwives used in relation to the two domains of EDAM: clinical reasoning and midwifery practice, which are distinct but correlated, and their respective subscales. The clinical reasoning subscales are:

1. The clinical reasoning process - focuses on making the decision after balancing the alternatives.

2. Integration and interpretation - involves the addition of intuitive thinking and reflection during initiation and evaluation of the treatment.

The midwifery practice subscales are:

1. Women's relationship with the midwife - actions necessary to form and maintain the midwife-woman relationship.
2. General Midwifery Practice - concerns behaviors occurring within that relationship, which support or detract from good (optimal) decision making.

The two domains and subscales are scored on a 5-point Likert scale from Strongly Disagree (absent or negative influence) through Neither Agree or Disagree (neither positive nor negative) to Strongly Agree (very positive influence), thus acting as a rating scale to identify and grade the overall presence of the action/ behavior. The scoring of each variable underpinned the categorization of decision making into one of the four EDAM categories (see Figure 1). We used a process of investigator triangulation to validate the interpretation of the narratives against the EDAM. There was minimal disagreement between the researchers on the categorization of the narratives using EDAM (Jefford et al., 2016). Where discrepancy existed (two cases), this was then worked through collectively using the EDAM tool to identify the differences. Consensus was reached via discussion (Holloway \& Wheeler, 2004; Jirojwong \& Pepper, 2011). An independent researcher reviewed and validated the final data analysis.

\section{RESULTS}

\section{Decision-Making Categories}

The categorization of each narrative is presented in Table 1 (intact perineum) and Table 2 (perineal tear) as well as other basic data such as level of training. The majority of midwives engaged in good clinical reasoning, with only one narrative providing an example of poor clinical reasoning. However, overall only three examples of optimal decision making were evident, with both good clinical reasoning and midwifery practice identified.

\section{Good Clinical Reasoning}

Good clinical reasoning was evident through cue acquisition, cue clustering, and cue interpretation, which led in to ruling in and ruling out hypothesis, as demonstrated in Sarah's and Mary's narratives below. It is important to note not all steps in the clinical reasoning process appear to be essential or linear in order to reach a hypothesis. 


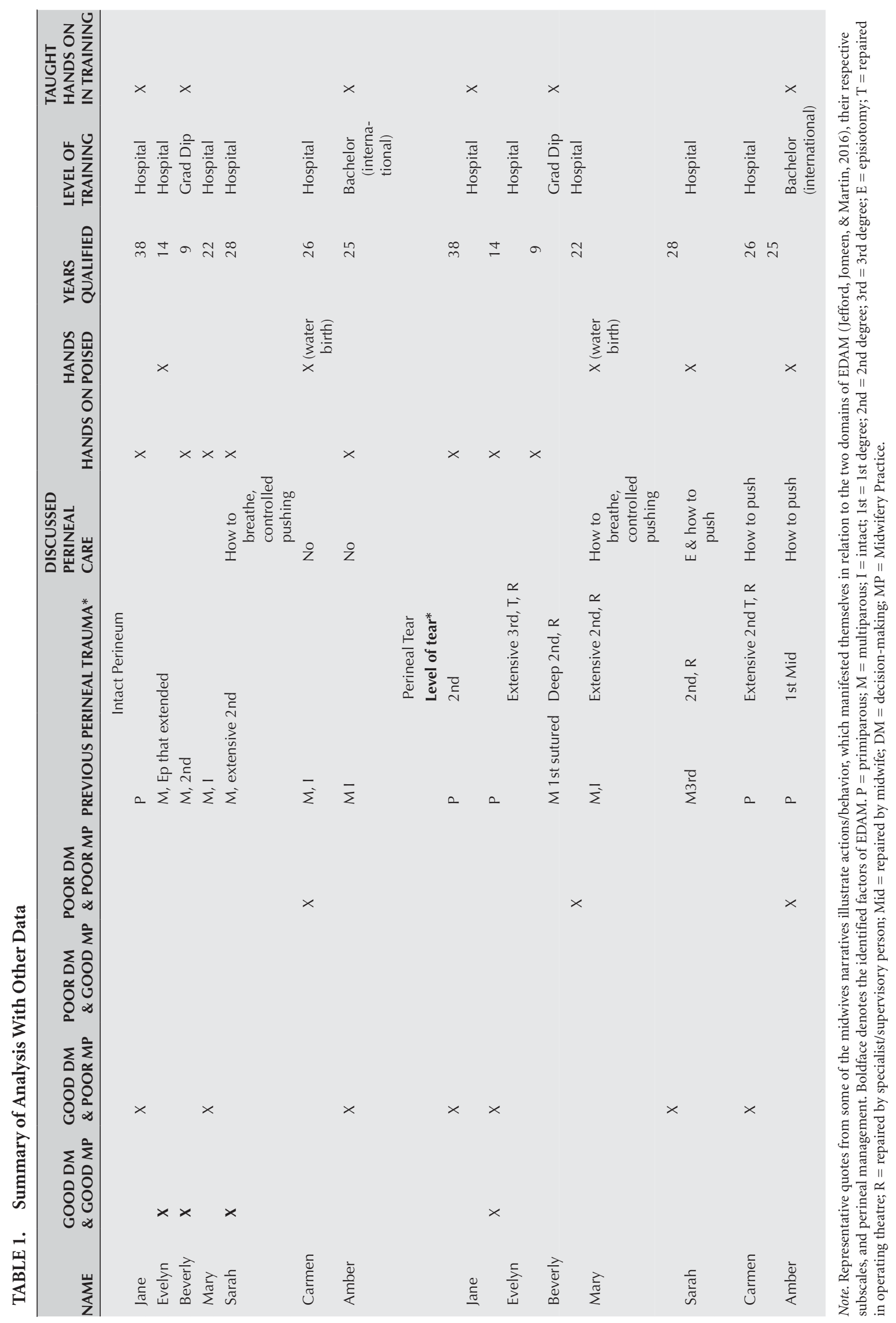




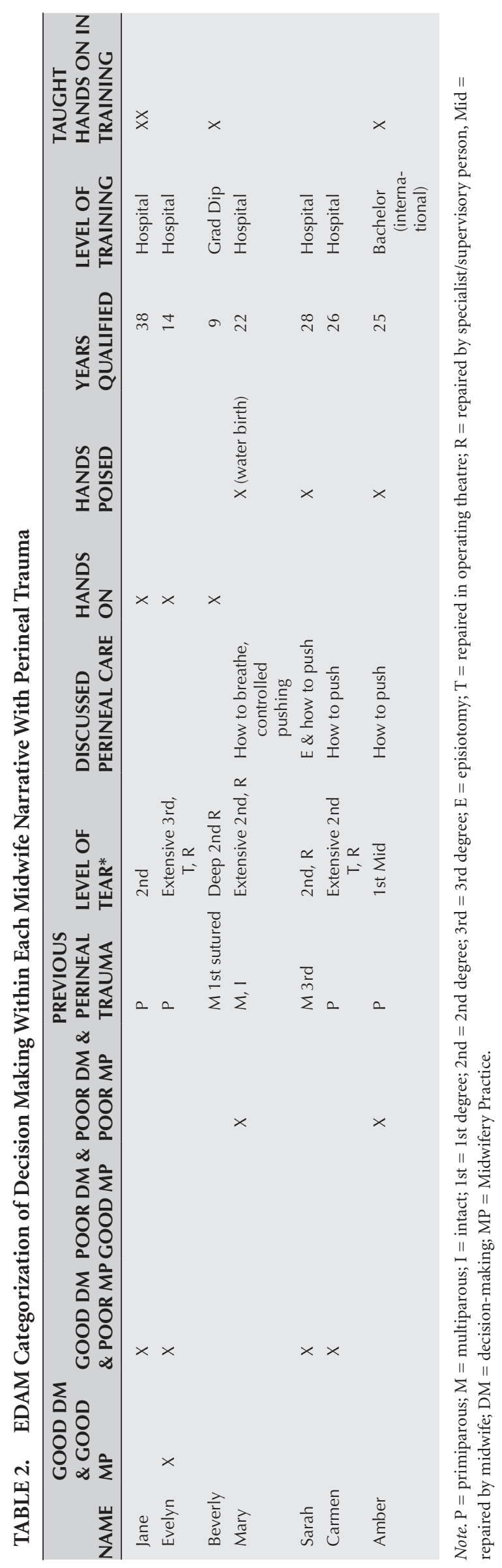


I could see the perineum was pink (cue acquisition), there were no signs of pocketing (cue acquisition), when it goes a whitish color and dimples, the bulb of the perineum was not showing signs of getting swollen (cue acquisition), or oedematous (cue acquisition), to indicate signs of obstructed labor (cue clustering/cue interpretation/ruling out hypothesis). Also there was no bleeding (cue acquisition), indicating it had started to tear superficially (ruling out hypothesis). [Sarah: perineal tear]

Midwives who engaged in good clinical reasoning also demonstrated evaluation of treatment options relevant to their hypothesis, evaluated outcomes and integrated intuition within their clinical reasoning. Beverley evidences this.

After 20 minutes, I decided to do a vaginal examination (prescribes care) to see if Stefanie's cervix was fully dilated (focused cue acquisition). Her cervix was fully dilated (evaluates outcome). Stefanie felt most comfortable in left lateral, with her leg up on my hip, and her other leg was bent up towards her chest. I felt anxious she liked this position because in my experience women in this position always suffer a perineal tear. I sort of think "you're going to get tear, because you're in the left lateral" (uses intuition). [Beverley: perineal tear]

Mary's narrative highlights reference to the evidence base, when stated in relation to treatment options, was often somewhat tenuous, despite the majority of midwives engaged in good clinical reasoning.

I encouraged Anna to try warm washers on Juliette's perineum as some women like it and it helps with the stinging pain (prescribing care). What I was really thinking about was the warm compresses would help perineal integrity on the perineum, because I've read that somewhere (evaluating treatment options). [Mary: intact perineum]
Clinical guidelines or teaching during training, rather than direct knowledge of the evidence base, appear to influence midwives' decision making. Educational training around "hands on" the perineum or "hands poised (off)" demonstrated this, with "hands on" the perineum more prevalent. The following two narratives demonstrate this.

We have a "hands on" policy (cue acquisition) and it was the way I was taught in my training... [Beverley: intact perineum]

I did worry about the perineum because you're not touching the baby's head in water and I do normally do controlled pressure on the baby's head when it's ... [Carmen: perineal tear]

\section{Poor Clinical Reasoning}

Midwives who demonstrated poor clinical reasoning still engaged in some aspects of the clinical reasoning process but failed to employ others. In Amber's narrative below, cue acquisition, cue clustering, and cue interpretation are evident throughout; there is no real use of the cue interpretation to guide practice or evidence of ruling in or ruling out alternate hypotheses. Despite the clear implementation of a "hands on" intervention, no other options are considered and no evaluation of the approach takes place.

I had full view of Grace's perineum, it was stretching beautifully (cue acquisition), and it was pink (cue acquisition). There was no perineal tissue holding the head back (cue acquisition), it didn't blanch (cue acquisition), it didn't show any signs of breaking in any nasty way (cue acquisition) and there was no evidence of bleeding (cue acquisition/clustering). But I'm old school and always have "hands on" to protect the perineum. I feel like it comes naturally to do so. [Amber: perineal tear]

\section{Good Midwifery Practice}

Midwives who demonstrated good midwifery practice engaged in effective communication to underpin the relationship with the woman, shared information which both defined and acknowledged common goals, and imbued trust in women's bodies to birth. As in Evelyn's narrative: 
As Suzy and I chatted she said she didn't want another episiotomy or another tear. We spoke about scar tissue from the episiotomy, and if the perineum looked like it wasn't going to stretch (rigid) to allow the baby to come out then we might need to do an episiotomy again (shares common known goal with the woman/honest and complete information sharing/assumes appropriate responsibility for woman/baby)....I encouraged Suzy to have a couple of pushes where she tightened her perineal muscles, then I coached her to relax the perineal muscles when pushing (shares common known goal/trust in woman and her body). Suzy was really responsive to the coaching and managed to let those muscles loose while she was pushing (shares common known goal/trust in woman and her body). She listened to what I was saying and she could feel the difference... [Evelyn: intact perineum]

\section{Poor Midwifery Practice}

This occurred when either the midwife-woman relationship was not well established; there were no attempts to share information and/or to determine a common goal. This left Jane, for example, feeling like she had no control, ultimately undermining her professional accountability. This compromised Jane's ability to undertake what she felt was the appropriate action, in light of good clinical reasoning.

During the first stage of labor I tried to talk to Kya about what her body was doing and why she was feeling things (honest and complete information sharing). I did try and talk about second stage and how it was important the baby's head was breathed out (honest and complete information sharing), but she was not listening and really just being uncooperative... Kya was out of control even her mother didn't have any control over her (cue acquisition, woman is the final decision-maker). I can say as a midwife I didn't have much control over her pushing or stopping her pushing (not accountable for own professional behavior in accordance with professional frameworks)...
I was thinking we might be lucky we might get away with just a little first degree or something (uses intuition)... The tension in the room definitely influenced my decisionmaking (shows reflexive practice). I couldn't make any decisions (not accountable for own professional behavior in accordance with professional frameworks), because she made them all (woman as final decision-maker): she made the decision she was going to do labor and birth her child like she did (woman as final decisionmaker). I just along with her even if I didn't think there were right (not accountable for own professional behavior in accordance with professional frameworks/does not take appropriate action [documentation and consultation] when the woman and midwife disagree). Maybe if I'd had longer with her in from the beginning maybe that might have been more helpful (shows reflexive practice) but in the hospital system when you met a woman when you arrive on shift you don't always get to know the person. [Jane: perineal tear].

Despite good clinical reasoning, Carmen's midwifery practice was poor, in accordance with EDAM's two domains and their subscales. In spite of early attempts to share information, the desired outcome (minimizing perineal injury) voiced as hers, rather than a truly shared goal between the midwife and woman. This theme carries on as Carmen continues strongly to focus on the "I" in the narrative and fails to revisit the situation with Sue in light of identifiable risk factors for perineal damage.

First stage of labor was uneventful...During that time we talked about what would be happening in second stage of labor (honest and complete information sharing). We talked about the perineum and how important it was for Sue to listen to me as I would be coaching her to push and what sort of breathing I would like her to do (prescribes care) when the baby's head was being born as I wanted to minimize any perineal tears (honest and compete information sharing but not a common known goal)... The perineum however started 
to "funnel up" (cue acquisition) around the baby's head. As the baby's head was slowly advanced the perineum started to form a fairly tight band around the head (cue acquisition). The perineum also started to look blanched (cue acquisition), all the color drained out of it (cue acquisition). So I start to ask myself questions: "Is the baby's head going to get past that band?" (cue interpretation). "If I just keep on pushing her to push this baby out, will the perineum just explode and there'll be tears everywhere?" (ruling in/out hypothesis). "Do I do an episiotomy?" (evaluating treatment options) I knew the perineum was tight (cue acquisition) and I was not sure I would have got my fingers in (cue interpretation) to infiltrate with local anesthetic. In the back of my mind was the thought that episiotomies aren't comfortable when they're repaired and can cause a lot of postnatal pain (evaluating treatment options). As there was no fetal distress (cue acquisition), I decided an episiotomy was the thing I want to do (no honest and complete information sharing/no sharing of a common goal with the woman/woman is not the final decision-maker). [Carmen: perineal tear]

There is a clear attempt by several midwives to actively gate-keep certain information, as the two examples below illustrate.

Gail and I talked about what I was going to ask her to do when it got to 2nd stage: how to use different positions, movement, and breathing techniques (shares common known goal/honest and complete information sharing). This was so when she got to that crucial part of second stage of losing control and being frightened and the pain is too much, it's not the first time she's heard of what I'm going to ask her to do or how I'm going to guide her and reassure her (shares common known goal/honest and complete information sharing/trusts the woman and her body). I asked Gail just to do the blowing "phh, phh, phh" when the head comes out (assumes appropriate responsibility for woman/baby well-being). I told her this should protect her perineum from tearing (honest and complete information sharing/ruling in a hypothesis). I chose not to mention the possibility of an episiotomy (not honest and complete information sharing) as she only had a second degree tear previously (cue acquisition) and I don't tend to discuss episiotomies with any woman (not honest and complete information sharing/no sharing of a common goal with the woman/woman is not the final decision-maker/ not accountable for own professional behavior in accordance with professional frameworks). [Beverley: intact perineum].

I chose not to voice any of my thoughts with Shannon as they're not things that are beneficial to tell her (not honest and complete information sharing) [Carmen: perineal tear].

\section{DISCUSSION}

We have presented evidence of some interesting issues in relation to midwives' decision making around perineal management, though as a small exploratory study some caution is required when viewing the results in this paper. It is pleasing to note only one narrative out of 14 narratives could be categorized as poor decision making using EDAM (Jefford et al., 2016).

By applying EDAM (Jefford et al., 2016) to midwives' perineal narratives, we aimed to provide further insight in to how midwives in a practice setting engaged in clinical reasoning within a midwifery philosophy. It is evident to reach a "good" decision, it is not essential to engage in all stages of the clinical reasoning process. Further, grouping together of the stages of the clinical reasoning process occurs. This may or may not be a conscious process by midwives. Cue acquisition, cue clustering, and cue interpretation occurred in all 14 narratives. Formulation of a hypothesis may be an important aspect in midwives progressing on to the integration and intervention phase of clinical reasoning. The failure to formulate $a$ hypothesis, as noted in one narrative, it seems, potentially prevents evaluation of treatment options occurring.

Midwives use intuition to aid decision making in the integration and intervention phase of clinical reasoning. Arguments whether intuition plays a key role in the provision of health care have occurred over the last 30 years (Benner, 1983, Benner, 2000; Benner, Stannard, \& Hooper, 1996). The findings from this study appear 
to add voice to that argument: intuition is demonstrated in the 13 narratives displaying good decision making. It is interesting to note, and maybe relevant, that the only example of poor decision making did not show evidence of intuition. It is difficult to ascertain whether this is linked to the failure to formulate a hypothesis here but may be an area worthy of further investigation.

This study raises interesting questions about how midwives consider relevant evidence within their practice. A significant influence on their practice appears to be how they had "been taught" during their original midwifery training to manage the perineum: for the majority this was a "hands-on" approach. This is despite evidence from the UK HOOP trial (McCandlish et al., 1998), a Cochrane review (Aasheim et al., 2011), and a structured review of the literature (Wang et al., 2015), which have been unable to unequivocally support a hands-on approach. Recent 2015 guidelines from the UK RCOG, however, advocate a hands-on approach in an attempt to reduce the incidence of 3rd- and 4thdegree tears (RCOG, 2015). Cooper (2016) denotes the feature of having hands-on to protect the perineum is all that is required. We content that other elements need to be considered such as good communication with the woman to help breath the head out slowly. The midwifery practice domain of EDAM incorporates communication as having key importance in the midwifewoman relationship.

Other elements of EDAM (Jefford et al., 2016) midwifery practice were also highly evident as lacking within midwives' narratives, such as the woman as the final decision-maker. This encompasses women feeling in control and having the autonomy to make individual choices about their own unique birthing journey. Women's autonomy is compromised if a midwife employs techniques (e.g., hands-on, which dictate a certain birthing position) in the face of ambivalent evidence. While we acknowledge it is possible to apply a hands-on technique in other positions, the optimal position in order for the midwife to have clear unhindered visualization, as well as enough room to apply the hands on the perineum maneuver, is for the woman to be on her back semi-recumbent or in a lithotomy or an upright position (Cooper, 2016; Petrocnik \& Marshall, 2015). If the optimal position is encouraged, it will limit both the woman's choice of birth position, feelings of control, and her role as a partner in decision making (Cooper, 2016). Further, this potentially compromises other elements of good midwifery practice, such as honest and complete information sharing, sharing a common known goal, and trust in the woman and her body. Hence, it is feasible to suggest the ambiguity of the evidence on perineal management, when combined with the pervading influence of midwives' education training, may be a contributing factor where midwives failed to demonstrate good midwifery practice.

Additional elements of good midwifery practice, absent in the midwifery narratives of this study, are midwives' accountability for their professional behavior in accordance with professional frameworks and appropriate responsibility for the woman and baby's wellbeing (Nursing and Midwifery Board of Australia, 2006, 2007; ICM, 2008, 2010, 2011; Nursing and Midwifery Council, 2008; Nursing and Midwifery Council, 2012). Previous work by Jefford and Jomeen (Jefford, 2012; Jefford \& Jomeen, 2015) identified how midwives abdicate their professional role while undertaking decision making in one of three interconnected ways. These include internalized perceptions of midwifery practice; knowing but failing to act; and prioritization of the woman's needs. In the midwives' narratives from this study, there is evidence that midwives engage in "midwifery abdication" in the context of perineal management.

Though more examples of midwifery abdication were evident in the narratives, the two examples of midwifery abdication presented are "knowing and failing to act" (Jane's narrative) and "internalized perceptions of midwifery practice" (Beverly's narrative). The unfortunate consequences of midwifery abdication are that it undermines the safety and efficacy of midwifery practice, destabilizes midwifery's right to claim professional autonomy, leads to relegation of clinical judgment because of the behaviors or perceived needs of women, and ultimately leaves midwives exposed to professional censure. Midwifery abdication in essence, renders midwives vulnerable, as the boundaries of the midwifewoman relationship are un-negotiated. Midwives while believing they are working for the woman are not working in partnership with the woman and are therefore compromising the woman's opportunity to make fully informed decisions. This is an area that is undoubtedly worthy of further investigation.

\section{LIMITATIONS}

This study is early exploratory work and there are some limitations, which require acknowledgment. The sample is small and drawn from a single site, which clearly influences the broader application of these findings. However, the application of EDAM (Jefford et al., 2016), a midwifery-specific decision-making tool, afforded a 
workable structured approach to analyzing qualitative data. EDAM (Jefford et al., 2016) offers potential transferability and replicability as a basis for future work, as well as offering some useful insights into how midwives approach perineal management.

\section{CONCLUSION}

Midwives in this study appear to engage in good clinical reasoning as an implicit process rather than an explicit process. Intuition appears integral to good clinical reasoning. Midwives' failure to engage in good clinical reasoning may result in compromising effective care. Midwives' ability to integrate evidence affects good midwifery practice and can result in midwifery abdication, which can compromise a midwife's professional accountability thus placing them in a vulnerable position from a regulatory perspective.

In addition, this study offers further support for the use of the EDAM tool as a useful framework for exploring midwives' decision making, incorporating both assessment of clinical reasoning and midwifery practice. Professional midwifery and legislative frameworks demand midwives practice in a safe and accountable way but in a manner that promotes the decisional autonomy of women. Using EDAM facilitates interrogation of those aspects in which midwives perform less effectively. This can provide a useful platform from which to design training and education packages. The application of EDAM to reflective accounts or even observational contexts in practice would facilitate practice-based support and supervision and ultimately promote transparent and defensible decision making.

\section{REFERENCES}

Aasheim, V., Nilsen, A. B., Lukasse, M., Reinar, L. M (2011). Perineal techniques during the second stage of labour for reducing perineal trauma. The Cochrane database of systematic reviews, (12), CD006672. http://dx.doi.org/ 10.1002/14651858.CD006672.pub2

Benner, P. (1983). Uncovering the knowledge embedded in clinical practice. Image: the Journal of Nursing Scholarship, 15(2), 36-41. http://dx.doi.org/10.1111/j.15475069.1983.tb01353.x

Benner, P. (2000). The wisdom of our practice. The American Journal of Nursing, 100(10), 99-105.
Benner, P., Stannard, D., \& Hooper, P. L. (1996). A “thinkingin-action" approach to teaching clinical judgment: a classroom innovation for acute care advanced practice nurses. Advanced Practice Nursing Quarterly, 1(4), 70-77.

Bulchandani, S., Watts, E., Sucharitha, A., Yates, D., \& Ismail, K. M. (2015). Manual perineal support at the time of childbirth: A systematic review and meta-analysis. BJOG: An International Journal of Obstetrics \& Gynaecology, 122(9), 1157-1165. http://dx.doi.org/10.1111/ 1471-0528.13431

Cioffi, J. M., Arundell, F., \& Swain, J. (2009). Clinical decision-making for repair of spontaneous childbirth trauma: Validation of cues and related factors. Journal of Midwifery \& Women's Health, 54(1), 65-72. http:// dx.doi.org/10.1016/j.jmwh.2008.05.010

Cioffi, J. M., Swain, J., \& Arundell, F. (2010). The decision to suture after childbirth: cues, related factors, knowledge and experience used by midwives. Midwifery, 26(2), 246-255. http://dx.doi.org/10.1016/j.midw.2008.05.004

Cluett, E. R., \& Burns, E. (2009). Immersion in water in labour and birth. Cochrane Database of Systematic Reviews, (2) CD000111. http://dx.doi.org/10.1002/ 14651858.CD000111.pub3

Cooper, T. (2016). 'Hands on' or 'hands off'. The Practising Midwife, 19(2), 32-34.

Dahlen, H. (2007). Reduction of perineal trauma and improved perineal comfort during and after childbirth: The perineal warm pack trial. Unpublished doctoral dissertation, University of Technology Sydney.

Dahlen, H. G., \& Homer, C. S. (2008). What are the views of midwives in relation to perineal repair? Women and Birth, 21(1), 27-35. http://dx.doi.org/10.1016/j.wombi. 2007.12.003

Gupta, J., Hofmeyer, G., \& Shehmar, M. (2012). Position in the second stage of labour for women without epidural anaesthesia. Cochrane Database Systematic Reviews, 16(5), CD002006.

Gurol-Urganci, I., Cromwell, D. A., Edozien, L. C., Mahmood, T. A., Adams, E. J., Richmond, D. H., . . . van der Meulen, J. H. (2013). Third- and fourth-degree perineal tears among primiparous women in England between 2000 and 2012: Time trends and risk factors. BJOG: An International Journal of Obstetrics \& Gynaecology, 120(12), 1516-1525. http://dx.doi.org/10.1111/14710528.12363

Hauck, Y. L., Lewis, L., Nathan, E. A., White, C., \& Doherty, D. A. (2015). Risk factors for severe perineal trauma during vaginal childbirth: A Western Australian retrospective cohort study. Women and Birth, 28(1), 16-20. http://dx.doi.org/10.1016/j.wombi.2014.10.007 
Holloway, I., \& Wheeler, S. (2004). Qualitative research in nursing (2nd ed). Oxford, UK: Blackwell publising.

International Confederation of Midwives. (2008). ICM International Code Of Ethics for Midwives. Retrieved from http://www.internationalmidwives.org

International Confederation of Midwives. (2010). Essential Competencies for Basic Midwifery Practice. Retrieved from www.internationalmidwives.org

International Confederation of Midwives. (2011). Definition of the midwife. Retrieved from http://www.internationalmidwives.org

Jefford, E. (2012). Optimal midwifery decision-making during 2nd stage labour: The integration of clinical reasoning into practice. (PhD Research). New South Wales, Australia: Southern Cross University.

Jefford, E., \& Jomeen, J. (2015). “Midwifery Abdication": A finding from an interpretive study. International Journal of Childbirth, 5(3), 116-125. http://dx.doi.org/10. 1891/2156-5287.5.3.116

Jefford, E., Jomeen, J., \& Martin, C. R. (2016). Determining the psychometric properties of the Enhancing Decision-making Assessment in Midwifery (EDAM) measure in a cross cultural context. BMC Pregnancy and Childbirth, 16(1), 95-106. http://dx.doi.org/10. 1186/s12884-016-0882-3

Jirojwong, S., \& Pepper, K. (2011). Quantitative research design. In S. Jirojwong, M. Johnson, \& A. Welch (Eds.), Research methods in nursing \& midwifery: Pathways to evidence-based practice (pp. 136-164). Australia: Oxford University Press.

Kapoor, D. S., Thakar, R., \& Sultan, A. H. (2015). Obstetric anal sphincter injuries: review of anatomical factors and modifiable second stage interventions. International Urogynecology Journal, 26(12), 1725-1734. http://dx. doi.org/10.1007/s00192-015-2747-0

Kettle, C., \& Tohill, S. (2011). Perineal care. Clinical Evidence, 4, 1401-1440.

Komorowski, L. K., Leeman, L. M., Fullilove, A. M., Bedrick, E. J., Migliaccio, L. D., \& Rogers, R. G. (2014). Does a large infant head or a short perineal body increase the risk of obstetrical perineal trauma? Birth, 41(2), 147-152. http://dx.doi.org/10.1111/birt.12101

Lumbiganon, P., Laopaiboon, M., Gülmezoglu, A. M., Souza, J. P., Taneepanichskul, S., Ruyan, P., . . . Villar, J, al., e.., \& World Health Organization Global Survey on Maternal and Perinatal Health Research Group. (2010). Method of delivery and pregnancy outcomes in Asia: The WHO global survey on maternal and perinatal health 2007-08. The Lancet, 375(9713), 490-499. http://dx.doi.org/10.1016/S01406736(09)61870-5
Mazza, F., Kitchens, J., Kerr, S., Markovich, A., Best, M., \& Sparkman, L. P. (2007). Clinical excellence series. Eliminating birth trauma at Ascension Health. Joint Commission Journal on Quality \& Patient Safety, 33(1), 15-24.

McCandlish, R., Bowler, U., van Asten, H., Berridge, G., Winter, C., Sames, L., . . Elbourne, D. (1998). A randomised controlled trial of care of the perineum during second stage of normal labour. BJOG: An International Journal of Obstetrics and Gynaecology, 105(12), 1262-1272. http://dx.doi.org/10.1111/j.1471-0528. 1998.tb10004.x

Nursing and Midwifery Board of Australia. (2006). National competency standards for the midwife. Melbourne, Australia: Nursing and Midwifery Board of Australia.

Nursing and Midwifery Board of Australia. (2007). A national framework for the development of decision-making tools for nursing and midwifery practice. Retrieved from http://www.nursingmidwiferyboard.gov.au/ Codes-Guidelines-Statements/Frameworks/Frameworkfor-assessing-national-competency-standards.aspx

Nursing and Midwifery Board of Australia. (2008). Code of professional conduct for midwives in australia. Melbourne, Australia: Nursing and Midwifery Board of Australia.

Nursing and Midwifery Council. (2008). The Code: Standards of conduct, performance and ethics for nurses and midwives.

Nursing and Midwifery Council. (2012). Midwives rules and standards. Retrieved from http://www.nipec.hscni.net/ midwivesandmedicines/NMC-Midwives-rules-andstandards-2012.pdf

Petrocnik, P., \& Marshall, J. E. (2015). Hands-poised technique: The future technique for perineal management of second stage of labour? A modified systematic literature review. Midwifery, 31(2), 274-279. http://dx. doi.org/10.1016/j.midw.2014.10.004

Priddis, H., Dahlen, H. G., Schmied, V., Sneddon, A., Kettle, C., Brown, C., \& Thornton, C. (2013). Risk of recurrence, subsequent mode of birth and morbidity for women who experienced severe perineal trauma in a first birth in New South Wales between 2000-2008: A population based data linkage study. BMC Pregnancy and Childbirth, 13, 89-89. http://dx.doi.org/10.1186/ 1471-2393-13-89

Priddis, H., Schmied, V., \& Dahlen, H. (2014). Women's experiences following severe perineal trauma: a qualitative study. BMC Women's Health, 14(1), 32. http://dx.doi. org/10.1186/1472-6874-14-32

Ratier, N., Balenbois, E., Letouzey, V., Marès, P., \& de Tayrac, R. (2015). [Methods of pushing at vaginal delivery and pelvi-perineal consequences. Review]. Progres en 
urologie: journal de l'Association francaise d'urologie et de la Societe francaise d'urologie, 25(4), 180-187. http:// dx.doi.org/10.1016/j.purol.2015.01.003

Revicky, V., Nirmal, D., Mukhopadhyay, S., Morris, E. P., \& Nieto, J. J. (2010). Could a mediolateral episiotomy prevent obstetric anal sphincter injury? European Journal of Obstetrics \& Gynecology and Reproductive Biology, 150(2), 142-146. http://dx.doi.org/10.1016/j. ejogrb.2010.03.002

Royal College of Obstetricians and Gynaecologists. (2015). The Management of Third-and Fourth-Degree Perineal Tears: Green-top Guideline (Vol. 29, pp. 1-19). London, UK: Royal College of Obstetricians and Gynaecologists.

Spendlove, Z. (2005). To suture or not to suture? Decisions, decisions, decisions. A grounded theory study exploring the decision-making processes of midwives regarding management of perineal trauma following spontaneous childbirth. Evidence Based Midwifery, 3, 1479-4489.

Wang, H., Jayasekara, R., \& Warland, J. (2015). The effect of "hands on" techniques on obstetric perineal laceration: A structured review of the literature. Women and Birth: Journal of the Australian College of Midwives, 1-5.

Zare, O., Pasha, H., \& Faramarzi, M. (2014). Effect of perineal massage on the incidence of episiotomy and perineal laceration. Health, 06(01), 10-14. http://dx.doi.org/10. 4236/health.2014.61003

Zeiki, Z. L., Hilder, L., \& Sullivan, E. A. (2010). Australia's mothers and babies 2010: Perineal statistics series. Retrieved from https://www.aihw.gov.au/reports/moth- ers-babies/australias-mothers-babies-2010/contents/ table-of-contents

Correspondence regarding this article should be directed to Elaine Jefford, PhD, MSc, Post Grad Dip T\&L, BSc(Hons) Midwifery,BSc(Hons) Nursing, Research Lead-Midwifery, Southern Cross University, School of Health \& Human Sciences - Hogbin Drive, Coffs Harbour, NSW 2450, Australia. E-mail: elaine.jefford@scu.edu.au

Elaine Jefford, PhD, MSc, Post Grad Dip T\&L, BSc(Hons) Midwifery, BSc(Hons) Nursing- Research Lead-Midwifery, Southern Cross University, School of Health \& Human Sciences - Hogbin Drive, Coffs Harbour, NSW, Australia Adjunct Clinical Fellow Hull University.

Julie Jomeen, $\mathrm{PhD}, \mathrm{RM}, \mathrm{RGN}$, Professor, Dean: Faculty of Health and Social Care - University of Hull Dearne 103 University of Hull, UK - Adjunct Professor Southern Cross University, Australia.

Frances Guy, BA (hons) psychology, clinical midwifery consultant, North Mid Coast Local Health District, NSW, Australia.

Belinda Newcombe, RM, clinical midwifery educator,-Coffs Harbour Health Campus, North Mid Coast Local Health District, NSW, Australia.

Colin Martin, PhD, professor of mental health, Faculty of Society and Health, Buckinghamshire New University, UK Adjunct Professor Southern Cross University, Australia. 